\title{
Normal values of heart rate variability at rest in a young, healthy and active Mexican population
}

\author{
Marina Medina Corrales ${ }^{1}$, Blanca de la Cruz Torres ${ }^{2}$, Alberto Garrido Esquivel ${ }^{1}$, \\ Marco Antonio Garrido Salazar ${ }^{1}$, José Naranjo Orellana ${ }^{3^{*}}$ \\ ${ }^{1}$ Sports Organisation Faculty, Autonomous University of Nuevo León, Monterrey, Mexico \\ ${ }^{2}$ University of Seville, Seville, Spain \\ ${ }^{3}$ Pablo de Olavide University, Seville, Spain; *Corresponding Author: jnarore@upo.es
}

Received 8 April 2012; revised 27 April 2012; accepted 11 May 2012

\begin{abstract}
This study analyzed Heart Rate Variability in a large sample of active young subjects within a narrow age range (18 to 25), using time and frequency domain methods and a Poincaré plot. Heart rate was recorded (beat to beat) for 30 minutes at rest in $\mathbf{2 0 0}$ healthy subjects divided into 4 groups: 50 sportsmen (20.54 \pm 1.52 years); 50 active men (21.22 \pm 1.31 years); 50 sportswomen (20.10 \pm 1.87 years) and 50 active women (20.92 \pm 1.87 years). Significant differences were found for most parameters between athletes and active subjects (male and female) but not between genders. Percentile distributions were provided for all parameters (according to gender and physical activity level) to be used as references in future researches.
\end{abstract}

Keywords: Heart Rate Variability; Time Domain; Frequency Domain; Poincaré Plot

\section{INTRODUCTION}

Heart Rate Variability (HRV) is considered a good indicator of autonomic control related to cardiovascular health, and has been studied in a range of situations in order to determine the variables that influence it. The most widely-reported influential variables are: age [1-6], gender [5-8], heart disease [9], neurological disease [1012] and exercise [6,9,13-16]. HRV is known to decrease when sympathetic activity predominates, whereas it increases when parasympathetic activity predominates. HRV thus reflects autonomic control of the cardiovascular system [17].

Different methods are available for the analysis of HRV. According to the European Society of Cardiology and the North American Society of Pacing and Electrophysiology [18], the most widely-used methods are those in the time and frequency domains, together with the Poincaré plot [19] as the only common technique in the complex field of non-linear methods.

In patients with chronic heart failure (CHF) and acute myocardial infarction (AMI) it is accepted that the best prognostic information is provided by two methods in the time domain: the standard deviation of the intervals between normal beats (SDNN) [18,20-22] and the pNN50 (a measure of the number of adjacent $\mathrm{NN}$ intervals which differ by more than $50 \mathrm{~ms}$ ) [23], although the Task Force [18] recommends rMSSD better than pNN50 because its higher mathemathical robustness. A SDNN value of less than $50 \mathrm{~ms}$ or pNN50 lower than 3\% is considered indicative of high risk; a SDNN of between 50 and 100 indicates moderate risk, while a value of over $100 \mathrm{~ms}$ or a pNN50 greater than 3\% is considered normal [18].

Useful reference data are thus available in the time domain for the evaluation of HRV at rest, although they are related to the assessment of cardiovascular risk; it is not clear whether they can be extrapolated to healthy young people, or to what extent they are meaningful for judging the significance of other factors, such as exercise. However, there are no valid reference data for assessing parameters in the frequency domain or the Poincaré plot. It is only possible to interpret data in the light of earlier studies (mostly based on small samples in specific situations) but the values of high and low frequency (HF and LF) and the transversal and longitudinal diameters of the Poincaré plot (SD1 and SD2) are the tools used most to assess the autonomic control of the cardiovascular system.

Given the increasing use of HRV in various fields of medicine and physiology, the authors firmly believe that reference data must be provided for a large population of healthy people, taking age and gender into account. Having taking into account that age is the main factor conditioning HRV, due to a decrease of variability with aging [1-6], we thought it would be useful to provide data of a large population in a narrow age range. 
The aim of the present study is to analyze HRV in a large sample of active young mexican subjects (athletes and non-athletes) from 18 to 24 years old, using time and frequency domain methods and the Poincaré plot to provide reference data for future studies.

\section{METHODS}

A total of 200 subjects (100 male, 100 female) of Mexican nationality, aged 18 to 24, were selected from the student population of the Autonomous University of Nuevo León (Monterrey, Mexico).

All subjects were active and with unknown disease history. All of them were recruited voluntarily to complete the same number of males than females. All subjects were surveyed about their medical history to rule out diagnosed pathologies or drugs intake.

Half of the subjects (male and female) systematically trained for at least 6 hours a week and took part in competitions, playing for university teams. The other half of the subjects had an active lifestyle but without practicing sports regularly.

The total sample was thus divided into 4 groups: 50 sportsmen (SM group, age $20.54 \pm 1.52$ years, height $1.77 \pm 0.14 \mathrm{~cm}$, weight $73.50 \pm 10.32 \mathrm{~kg}$ ); 50 active men (AM group, age $21.22 \pm 1.31$ years, height $1.73 \pm 0.06$ $\mathrm{cm}$, weight $74.59 \pm 10.86 \mathrm{~kg}$ ); 50 sportswomen (SW group, age $20.10 \pm 1.87$ years, height $1.63 \pm 0.07 \mathrm{~cm}$, weight $61.53 \pm 9.53 \mathrm{~kg}$ ) and 50 active women (AW group, age $20.92 \pm 1.87$ years, height $1.61 \pm 0.05 \mathrm{~cm}$, weight $62.07 \pm 10.90 \mathrm{~kg}$ ).

All subjects were informed of study content and gave written consent in accordance with the Declaration of Helsinki. All subjects completed a questionnaire about their medical history.

Heart rate was recorded for 30 minutes at rest in a supine position, using a Polar RS800sd ${ }^{\circledR}$ monitor in RR mode (beat to beat) [24].

These records were logged by the computer through an infrared interface (Polar IR), using the Polar Precision Performance software package (version 5). A time series was obtained and exported to Excel 2007 and SPSS Version 15.0 for analysis.

Following the recommendations of the European Society of Cardiology and the North American Society of Pacing and Electrophysiology [18], the following parameters were calculated in the time domain: mean $\mathrm{NN}$, SDNN, SDNN index (the mean of SDNN), SDANN (the standard deviation of averaged NN intervals over 5 minute periods), rMSSD (the root mean square differences of successive NN intervals) and pNN50. In the frequency domain, the frequency spectrum was assessed using the Fast Fourier Transform to determine very low frequency (VLF), low frequency (LF), high frequency (HF), the
LF/HF ratio, and total power. In accordance with previous studies, other pNNx values for $\mathrm{x}=40,30,20$ and 10 $[25,26]$ were also calculated.

The Poincaré scatter plot was studied as a nonlinear tool. This plot provides information on autonomic activity in the heart, since the transverse axis (SD1) is considered an indicator of parasympathetic activity and the longitudinal axis (SD2) an inverse function of sympathetic activity [27-29]. Moreover, the SD2/SD1 ratio is considered to reflect sympathovagal balance.

Average, Standard Deviation and Percentiles 5, 10, 25, 50, 75, 90 and 95 were calculated for all parameters. The Shapiro-Wilk test was used to test for normal distribution. The Kruskal-Wallis nonparametric test was used to evaluate differences between the four groups, while the Games-Howell test was used as a post-hoc test for multiple comparisons. In all cases, a p value lower than 0.05 (null hypothesis rejected) was considered significant.

\section{RESULTS}

Tables 1 and $\mathbf{2}$ show the time and frequency domain values and the axis of the Poincaré plot for male (SM and $\mathrm{AM}$ ) and female groups (SW and AW), respectively.

Table 1. Time and frequency domain analysis and diameters of the Poincaré scatter plot for men (SM and AM). Values are expressed as mean \pm standard deviation. ${ }^{*} \mathrm{p}<0.05$; ${ }^{* *} \mathrm{p}<0.01$; **** $<0.001$.

\begin{tabular}{|c|c|c|c|c|}
\hline & \multicolumn{2}{|c|}{ SM } & \multicolumn{2}{|c|}{$\mathbf{A M}$} \\
\hline & Mean & SD & Mean & SD \\
\hline \multicolumn{5}{|l|}{ TIME DOMAIN } \\
\hline Mean NN (ms) $)^{* * *}$ & 993.47 & 134.01 & 905.90 & 117.38 \\
\hline SDNN (ms) ${ }^{*}$ & 101.19 & 37.38 & 83.07 & 31.68 \\
\hline Index SDNN (ms) ${ }^{*}$ & 92.28 & 34.48 & 74.40 & 29.04 \\
\hline SDANN (ms) & 41.47 & 41.47 & 33.52 & 17.68 \\
\hline rMSSD (ms) ${ }^{*}$ & 76.83 & 36.53 & 55.85 & 31.96 \\
\hline pNN50 (\%) & 18.80 & 7.71 & 12.81 & 8.29 \\
\hline pNN40 (\%) & 22.84 & 7.37 & 16.59 & 8.71 \\
\hline pNN30 (\%) & 27.71 & 6.65 & 21.51 & 8.74 \\
\hline pNN20 (\%) & 33.14 & 6.04 & 28.10 & 8.03 \\
\hline pNN10 (\%) & 39.30 & 5.21 & 36.49 & 6.39 \\
\hline \multicolumn{5}{|c|}{ FREQUENCY DOMAIN } \\
\hline Total power (ms²) & 88203.61 & 65832.76 & 63678.43 & 46251.43 \\
\hline $\operatorname{VLF}\left(\mathrm{ms}^{2}\right)$ & 83076.38 & 62379.12 & 60441.94 & 43561.91 \\
\hline $\mathbf{L F}\left(\mathrm{ms}^{2}\right)$ & 2534.91 & 2036.84 & 1728.43 & 1552.67 \\
\hline HF $\left(\mathrm{ms}^{2}\right)$ & 2592.32 & 2392.00 & 1508.07 & 1876.68 \\
\hline Ratio LF/HF & 128.78 & 65.79 & 174.03 & 157.75 \\
\hline \multicolumn{5}{|l|}{ POINCARÉ PLOT } \\
\hline SD1 (ms) ${ }^{*}$ & 57.01 & 25.32 & 42.05 & 21.97 \\
\hline SD2 (ms) ${ }^{*}$ & 134.13 & 46.82 & 111.07 & 39.62 \\
\hline Ratio SD2/SD1 ${ }^{*}$ & 2.49 & 0.56 & 2.84 & 0.71 \\
\hline
\end{tabular}


Table 2. Time and frequency domain analysis and diameters of the Poincaré scatter plot for women (SW and AW). Values are expressed as mean \pm standard deviation. ${ }^{* *} \mathrm{p}<0.01$; ${ }^{* * * *} \mathrm{p}<$ 0.001 .

\begin{tabular}{|c|c|c|c|c|}
\hline & \multicolumn{2}{|c|}{ SW } & \multicolumn{2}{|c|}{ AW } \\
\hline & Mean & SD & Mean & SD \\
\hline \multicolumn{5}{|l|}{ TIME DOMAIN } \\
\hline Mean NN (ms) $)^{* * *}$ & 977.30 & 129.35 & 874.67 & 118.49 \\
\hline SDNN (ms) ${ }^{* * *}$ & 106.62 & 38.15 & 71.78 & 24.48 \\
\hline SDNN Index (ms) ${ }^{* *}$ & 95.34 & 33.05 & 65.13 & 21.91 \\
\hline SDANN (ms) & 39.46 & 22.51 & 29.62 & 35.79 \\
\hline $\operatorname{rMSSD}(\mathbf{m s})^{* * *}$ & 89.60 & 40.46 & 50.70 & 28.67 \\
\hline pNN50 (\%) & 22.68 & 6.85 & 11.55 & 8.85 \\
\hline pNN40 (\%) & 26.75 & 6.45 & 15.35 & 9.59 \\
\hline pNN30 (\%) & 31.14 & 5.91 & 20.67 & 9.82 \\
\hline pNN20 (\%) & 35.86 & 4.92 & 27.68 & 9.16 \\
\hline pNN10 (\%) & 41.31 & 3.60 & 36.90 & 6.75 \\
\hline \multicolumn{5}{|c|}{ FREQUENCY DOMAIN } \\
\hline Total power $\left(\mathrm{ms}^{2}\right)^{* *}$ & 88599.12 & 68513.28 & 51211.93 & 30881.11 \\
\hline $\operatorname{VLF}\left(\mathrm{ms}^{2}\right)^{* *}$ & 83001.95 & 65834.88 & 48836.59 & 29620.35 \\
\hline $\mathbf{L F}\left(\mathrm{ms}^{2}\right)^{* * *}$ & 2327.63 & 1678.84 & 1158.79 & 780.92 \\
\hline $\mathrm{HF}\left(\mathrm{ms}^{2}\right)^{* * *}$ & 3269.53 & 3087.71 & 1216.55 & 1504.64 \\
\hline Ratio LF/HF ${ }^{* *}$ & 97.22 & 59.97 & 193.24 & 198.71 \\
\hline \multicolumn{5}{|l|}{ POINCARÉ PLOT } \\
\hline SD1 (ms) $)^{* * *}$ & 65.39 & 28.15 & 38.79 & 19.51 \\
\hline SD2 (ms) ${ }^{* * *}$ & 140.60 & 51.34 & 95.39 & 29.82 \\
\hline Ratio SD2/SD1 & 2.30 & 0.92 & 2.70 & 0.78 \\
\hline
\end{tabular}

Significant differences were found only between athletes and active subjects (both male and female). In the group of men, these differences were present in all parameters of the time domine (except SDANN and pNN10) and the diameters of Poincaré Plot (SD1 and SD2), but not in the parameters of the frequency domine. In the case of women, the differences were higher and were present in all the variables except SDANN and LF/HF ratio. When males and females were compared, no significant differences were recorded between AM and AW for any of the variables, as well as between SM and SW except for pNN50 (p=0.044), pNN40 (p=0.029) and pNN30 ( $=0.038)$.

Tables 3-6 show percentiles 5, 10, 25, 50, 75, 95 and 100 for parameters in the time and frequency domains and the Poincaré plot for male and female groups.

\section{DISCUSSION}

As indicated earlier, the Task Force of the European Society of Cardiology and the North American Society of Pacing and Electrophysiology [18] has provided valid reference data in the time domain for the assessment of cardiovascular risk. However, it is not clear whether they can be extended to healthy young people or to other variables such as degree of exercise. There are no solid reference data for the evaluation of parameters in the frequency domain or the Poincaré plot.

A recent review [30] highlights the limitations of the Task Force references and the difficulties in implementing values from subsequent studies. In light of this review they collect values that can serve as reference, but not separated by sex or age. Morover, they do not report values for Poincaré Plot.

A common problem affecting most studies of HRV is the small size and heterogeneity of the samples used, especially when sportpeople are concerned (15). This study therefore used 200 age-matched subjects classified into four groups according to gender and to whether or not they practiced a competitive sport; all subjects were active and had no history of disease.

The main contribution of this study is to provide percentile values of HRV in the time domain, frequency domain and Poincaré plot for a population of healthy, active young people in a narrow age-range. The most important factor to control was age, since the dynamics of the NN interval are known to vary with age in healthy people [31], not only comparing childhood to old age, but also in intermediate age ranges (for example from 30 to 40 years old) [32-35].

It will, of course, be necessary to provide values for other age ranges in the future; comparable data for other age groups, provided by the present researchers or others, will help to expand the available reference data.

With respect to the nationality of the sample, the only similar study found (although with a smaller and older population) is that of Lerma et al. [36], using Mexican subjects (30 females and 20 males) aged between 21 and 36.

Regarding the duration of the time series, 30 minutes is sufficient to obtain an optimal series of data ( $\mathrm{NN}$ intervals) for analysis [18]. Moreover, experience and theoretical knowledge for physiological interpretation are both greater for this recording period. Most of HRV studies with athletes and healthy people use short term records of ten minutes or less $(5,6,16,37)$ and it is known that the effect size is higher as the record is shorter [38].

The data obtained in the present study in the time domain showed that all parameters (except SDANN and pNN10) were significantly greater for athletes than for active subjects, both for males (Table 1) and females 
Table 3. Percentiles 5, 10, 25, 50, 75, 90 and 95 for parameters in the time domain for male groups.

\begin{tabular}{|c|c|c|c|c|c|c|c|c|}
\hline \multicolumn{9}{|l|}{ MEN } \\
\hline \multirow{2}{*}{ TIME DOMAIN } & & \multicolumn{7}{|c|}{ Percentiles } \\
\hline & & 5 & 10 & 25 & 50 & 75 & 90 & 95 \\
\hline \multirow{2}{*}{ Mean NN (ms) } & Sport & 803.06 & 855.14 & 890.94 & 946.58 & 1106.18 & 1214.41 & 1246.40 \\
\hline & Active & 697.50 & 752.85 & 818.56 & 890.51 & 1016.22 & 1048.82 & 1094.81 \\
\hline \multirow{2}{*}{ SDNN (ms) } & Sport & 52.27 & 55.54 & 73.31 & 97.50 & 114.24 & 157.74 & 182.33 \\
\hline & Active & 45.15 & 49.73 & 60.56 & 76.01 & 98.01 & 130.01 & 154.70 \\
\hline \multirow{2}{*}{ SDNN INDEX (ms) } & Sport & 48.01 & 53.40 & 67.12 & 87.40 & 110.44 & 149.56 & 170.04 \\
\hline & Active & 36.98 & 43.64 & 55.66 & 69.17 & 85.61 & 119.30 & 140.49 \\
\hline \multirow{2}{*}{ SDANN (ms) } & Sport & 11.19 & 14.36 & 23.54 & 33.01 & 47.17 & 58.79 & 117.46 \\
\hline & Active & 13.53 & 14.50 & 20.37 & 29.88 & 43.34 & 54.31 & 74.36 \\
\hline \multirow{2}{*}{ rMSSD (ms) } & Sport & 37.61 & 39.65 & 48.13 & 63.26 & 98.11 & 140.25 & 159.54 \\
\hline & Active & 24.00 & 31.74 & 34.94 & 44.01 & 64.85 & 105.60 & 132.55 \\
\hline \multirow{2}{*}{ pNN50 (\%) } & Sport & 7.25 & 7.64 & 10.98 & 19.58 & 25.38 & 27.93 & 29.11 \\
\hline & Active & 1.73 & 3.62 & 6.19 & 10.09 & 19.31 & 25.53 & 27.29 \\
\hline \multirow{2}{*}{ pNN40 (\%) } & Sport & 11.57 & 12.06 & 15.15 & 23.99 & 28.66 & 31.84 & 32.52 \\
\hline & Active & 3.38 & 6.45 & 9.31 & 14.75 & 23.77 & 29.17 & 30.02 \\
\hline \multirow{2}{*}{ pNN30 (\%) } & Sport & 18.10 & 18.41 & 21.55 & 29.38 & 32.61 & 35.48 & 36.73 \\
\hline & Active & 6.84 & 11.49 & 14.99 & 20.45 & 28.99 & 33.01 & 34.09 \\
\hline \multirow{2}{*}{ pNN20 (\%) } & Sport & 24.45 & 25.38 & 28.99 & 34.52 & 36.88 & 39.41 & 41.56 \\
\hline & Active & 13.32 & 18.84 & 23.33 & 28.70 & 34.66 & 37.52 & 38.34 \\
\hline \multirow{2}{*}{ pNN10 (\%) } & Sport & 32.93 & 35.01 & 37.65 & 39.67 & 41.98 & 44.70 & 46.00 \\
\hline & Active & 26.87 & 31.28 & 34.12 & 37.35 & 40.49 & 42.51 & 43.62 \\
\hline
\end{tabular}

Table 4. Percentiles 5, 10, 25, 50, 75, 90 and 95 for the frequency domain and Poincaré plot parameters for male groups.

\begin{tabular}{|c|c|c|c|c|c|c|c|c|}
\hline \multicolumn{9}{|l|}{ MEN } \\
\hline \multirow{2}{*}{ FREQUENCY DOMAIN } & & \multicolumn{7}{|c|}{ Percentiles } \\
\hline & & 5 & 10 & 25 & 50 & 75 & 90 & 95 \\
\hline \multirow{2}{*}{ Total power $\left(\mathrm{ms}^{2}\right)$} & Sport & $22,300.67$ & $25,158.05$ & $40,917.97$ & $71,666.88$ & $105,879.50$ & $162,266.00$ & $257,358.12$ \\
\hline & Active & $15,685.49$ & $20,760.32$ & $28,349.61$ & $50,964.67$ & $88,817.50$ & $129,404.07$ & $178,543.85$ \\
\hline \multirow{2}{*}{ VLF $\left(\mathrm{ms}^{2}\right)$} & Sport & $20,180.77$ & $22,775.74$ & $38,936.65$ & $69,497.61$ & $100,431.46$ & $148,126.49$ & $244,943.14$ \\
\hline & Active & $14,986.15$ & $19,808.95$ & $26,388.55$ & $49,712.56$ & $85,595.44$ & $124,111.55$ & $167,879.63$ \\
\hline \multirow{2}{*}{$\mathbf{L F}\left(\mathbf{m s}^{2}\right)$} & Sport & 698.43 & 778.88 & 1319.69 & 1935.99 & 3322.53 & 4602.81 & 6873.72 \\
\hline & Active & 286.64 & 480.98 & 785.97 & 1237.79 & 2106.35 & 3490.81 & 5063.43 \\
\hline \multirow{2}{*}{ HF $\left(\mathrm{ms}^{2}\right)$} & Sport & 520.43 & 585.58 & 809.35 & 1799.03 & 3422.55 & 7092.06 & 7980.21 \\
\hline & Active & 244.39 & 370.97 & 472.73 & 652.22 & $1,693.35$ & 4220.72 & 6489.55 \\
\hline \multirow{2}{*}{ Ratio LF-HF } & Sport & 44.25 & 52.31 & 81.00 & 121.10 & 163.53 & 234.94 & 255.97 \\
\hline & Active & 61.03 & 65.89 & 76.95 & 142.35 & 185.70 & 354.51 & 431.90 \\
\hline \multirow{2}{*}{ POINCARÉ PLOT } & & \multicolumn{7}{|c|}{ Percentiles } \\
\hline & & 5 & 10 & 25 & 50 & 75 & 90 & 95 \\
\hline \multirow{2}{*}{ SD1 (ms) } & Sport & 28.97 & 31.65 & 37.28 & 47.40 & 71.75 & 100.36 & 114.45 \\
\hline & Active & 20.94 & 24.93 & 28.10 & 34.10 & 47.78 & 76.12 & 95.68 \\
\hline \multirow{2}{*}{ SD2 (ms) } & Sport & 68.74 & 79.33 & 100.73 & 130.90 & 152.55 & 200.02 & 237.87 \\
\hline & Active & 61.33 & 67.11 & 83.38 & 103.15 & 129.68 & 171.89 & 197.84 \\
\hline \multirow{2}{*}{ Ratio SD2/SD1 } & Sport & 1.75 & 1.77 & 2.09 & 2.43 & 2.85 & 3.37 & 3.51 \\
\hline & Active & 1.89 & 2.11 & 2.27 & 2.61 & 3.43 & 3.81 & 4.15 \\
\hline
\end{tabular}


Table 5. Percentiles 5, 10, 25, 50, 75, 90 and 95 for parameters in the time domain for female groups.

\begin{tabular}{|c|c|c|c|c|c|c|c|c|}
\hline \multicolumn{9}{|c|}{ WOMEN } \\
\hline \multirow{2}{*}{ TIME DOMAIN } & \multirow{2}{*}{ LEVEL OF ACTIVITY } & \multicolumn{7}{|c|}{ Percentiles } \\
\hline & & 5 & 10 & 25 & 50 & 75 & 90 & 95 \\
\hline \multirow{2}{*}{ Media NN (ms) } & Sport & 790.19 & 831.33 & 883.65 & 971.85 & 1055.54 & 1156.72 & 1273.70 \\
\hline & Active & 711.91 & 737.18 & 788.74 & 855.64 & 960.58 & 1027.75 & 1075.29 \\
\hline \multirow{2}{*}{ SDNN (ms) } & Sport & 56.18 & 61.64 & 79.33 & 97.93 & 137.64 & 162.15 & 178.42 \\
\hline & Active & 38.09 & 40.56 & 52.80 & 68.67 & 86.46 & 103.37 & 130.12 \\
\hline \multirow{2}{*}{ INDEX SDNN (ms) } & Sport & 51.70 & 56.08 & 75.92 & 86.40 & 118.59 & 140.72 & 150.81 \\
\hline & Active & 31.69 & 37.75 & 48.26 & 64.94 & 78.05 & 96.99 & 110.81 \\
\hline \multirow{2}{*}{ SDANN (ms) } & Sport & 15.51 & 17.78 & 20.85 & 32.15 & 55.89 & 72.30 & 76.72 \\
\hline & Active & 8.39 & 10.92 & 15.37 & 21.40 & 35.60 & 41.52 & 63.80 \\
\hline \multirow{2}{*}{ rMSSD (ms) } & Sport & 38.73 & 46.53 & 62.12 & 80.68 & 109.21 & 141.23 & 188.01 \\
\hline & Active & 17.44 & 23.69 & 29.82 & 41.64 & 61.74 & 97.55 & 123.74 \\
\hline \multirow{2}{*}{ pNN50 (\%) } & Sport & 6.58 & 14.86 & 18.85 & 23.17 & 27.66 & 30.98 & 32.35 \\
\hline & Active & 0.67 & 2.13 & 3.47 & 8.90 & 18.71 & 25.70 & 30.05 \\
\hline \multirow{2}{*}{ pNN40 (\%) } & Sport & 10.94 & 16.12 & 24.74 & 27.02 & 31.31 & 33.89 & 35.61 \\
\hline & Active & 1.27 & 3.98 & 6.60 & 15.46 & 23.39 & 28.95 & 32.98 \\
\hline \multirow{2}{*}{ pNN30 (\%) } & Sport & 15.11 & 21.31 & 29.88 & 31.80 & 34.54 & 37.02 & 39.16 \\
\hline & Active & 3.65 & 8.36 & 11.32 & 21.58 & 28.04 & 33.21 & 36.10 \\
\hline \multirow{2}{*}{ pNN20 (\%) } & Sport & 20.80 & 30.30 & 34.57 & 36.56 & 38.71 & 40.46 & 41.61 \\
\hline & Active & 9.69 & 16.85 & 20.42 & 30.25 & 35.08 & 39.00 & 39.65 \\
\hline \multirow{2}{*}{ pNN10 (\%) } & Sport & 33.77 & 37.14 & 39.76 & 41.62 & 43.81 & 45.33 & 46.08 \\
\hline & Active & 23.17 & 27.81 & 32.77 & 38.75 & 41.75 & 44.06 & 45.06 \\
\hline
\end{tabular}

Table 6. Percentiles 5, 10, 25, 50, 75, 90 and 95 for the frequency domain and Poincaré plot parameters for the groups of women.

\begin{tabular}{|c|c|c|c|c|c|c|c|c|}
\hline \multicolumn{9}{|c|}{ WOMEN } \\
\hline \multirow{2}{*}{ FREQUENCY DOMAIN } & \multirow{2}{*}{ LEVEL OF ACTIVITY } & \multicolumn{7}{|c|}{ Percentiles } \\
\hline & & 5 & 10 & 25 & 50 & 75 & 90 & 95 \\
\hline \multirow{2}{*}{ Total power $\left(\mathrm{ms}^{2}\right)$} & Sport & $20,507.00$ & $26,802.37$ & $40,786.42$ & $73,880.75$ & $110,844.21$ & $164,938.97$ & $265,497.77$ \\
\hline & Active & $11,458.25$ & $17,785.21$ & $27,353.82$ & $45,618.15$ & $65,726.16$ & $100,156.50$ & $119,441.76$ \\
\hline \multirow{2}{*}{$\operatorname{VLF}\left(\mathrm{ms}^{2}\right)$} & Sport & $17,956.42$ & $23,422.41$ & $36,421.54$ & $68,076.91$ & $100,822.85$ & $154,483.96$ & $250,987.25$ \\
\hline & Active & $10,831.28$ & $16,703.87$ & $25,203.14$ & $43,702.99$ & $62,454.32$ & $98,814.39$ & $113,293.42$ \\
\hline \multirow{2}{*}{$\mathbf{L F}\left(\mathrm{ms}^{2}\right)$} & Sport & 569.29 & 729.84 & 969.78 & 1849.80 & 2932.07 & 4704.38 & 5716.16 \\
\hline & Active & 189.14 & 356.08 & 601.04 & 1033.77 & 1482.59 & 2262.05 & 2863.56 \\
\hline \multirow{2}{*}{$\mathrm{HF}\left(\mathrm{ms}^{2}\right)$} & Sport & 504.60 & 688.28 & 1323.87 & 2117.74 & 4204.50 & 6723.68 & $11,270.62$ \\
\hline & Active & 89.33 & 160.55 & 354.57 & 683.88 & 1287.93 & 3579.91 & 5364.31 \\
\hline \multirow{2}{*}{ Ratio LF-HF } & Sport & 22.73 & 30.47 & 51.88 & 77.75 & 138.30 & 197.29 & 227.80 \\
\hline & Active & 41.73 & 51.18 & 72.25 & 123.65 & 225.05 & 507.19 & 763.51 \\
\hline \multirow{2}{*}{ POINCARÉ PLOT } & \multirow{2}{*}{ LEVEL OF ACTIVITY } & \multicolumn{7}{|c|}{ Percentiles } \\
\hline & & 5 & 10 & 25 & 50 & 75 & 90 & 95 \\
\hline \multirow{2}{*}{ SD1 (ms) } & Sport & 31.11 & 35.72 & 45.98 & 58.85 & 78.33 & 100.92 & 134.07 \\
\hline & Active & 18.43 & 20.17 & 24.90 & 32.70 & 45.20 & 70.32 & 88.27 \\
\hline \multirow{2}{*}{ SD2 (ms) } & Sport & 73.97 & 78.79 & 101.73 & 130.15 & 181.55 & 221.41 & 245.94 \\
\hline & Active & 52.96 & 55.05 & 73.08 & 90.85 & 115.73 & 135.70 & 161.58 \\
\hline \multirow{2}{*}{ Ratio SD2/SD1 } & Sport & 1.51 & 1.60 & 1.74 & 2.01 & 2.59 & 3.03 & 3.54 \\
\hline & Active & 1.70 & 1.83 & 2.11 & 2.49 & 3.10 & 3.85 & 4.47 \\
\hline
\end{tabular}


(Table 2). However, there was no significant difference between men and women with the same level of physical activity, except for pNN50, 40 and 30 between sportsmen and sportswomen (females showed higher values than males). This means that, according to our results, heartbeat signal displays significantly greater variability (assessed in the time domain) in men and women engageing in competitive sports, with no gender-related differences. This could be due to greater parasympathetic activity at rest $[39,40]$.

Other values can be used in place of pNN50 (40, 30, 20 and 10); Mietus et al [25] demonstrated that the discriminatory sensitivity of pNNx increased as the value of " $x$ " fell. Similar findings are reported by De la Cruz and Naranjo [26] when using pNNx to differentiate between healthy subjects and cardiac patients at rest and during exercise. Here, however, the statistic $\mathrm{pNNx}$ with $\mathrm{x}$ values between 10 and 50 showed no advantage over pNN50. Refferences for pNNx statistics is one further contribution of this study.

Many other authors have reported differences in HRV between trained and untrained people [6,9,13-16,36,41]. However, in some cases sample sizes were too small to be meaningful; in other cases did not differ between gender or age ranges were too broad. Perhaps the main contribution of the present study is the statistical power derived from a large sample size in a narrow range of age.

The comparison of HRV behaviour between women and men is a controversial issue. Some studies have found gender differences while others have not $[3,36]$. Anyway, even when differences are found, it seems clear that age had a greater impact on HRV than sex [16].

In the present study, there was no significant difference between men and women in the time domain; the only significant difference recorded was between sportsmen and sportswomen for pNN50 ( $\mathrm{p}=0.044)$, pNN40 (p $=0.0299)$ and $\mathrm{pNN} 30(\mathrm{p}=0.038)$. In any case, the level of physical activity was more decisive than gender in the time domain.

In the frequency domain, ultra low (ULF) [42], very low (VLF) [43] and low frequency (LF) [44,45] at rest are acknowledged to be good indicators of health in cardiac patients, but there is little information about healthy young people. In the present study, sportswomen displayed significantly higher values than active women for total power $(p=0.004), \operatorname{VLF}(p=0.007), \operatorname{LF}(p=0.0001)$ and HF $(p=0.010)$, and significantly lower values for the LF/HF ratio $(\mathrm{p}=0.009)$. No other differences (males vs. females or SM vs. AM) were significant. Sportswomen thus appear to display parasympathetic predominance compared to active women at rest; the authors cannot satisfactorily explain why these differences are not found for men.
A recent Meta-Analysis [38] reports a higher HF in trained subjects but they do not differ for gender or age. A paper with 145 track-and-field athletes (both sexes, from 18 to 33 years old) report values very similar to ours in the time domine but much lower than ours in the frequency domine [37].

Perini et al [46] observed no changes in HF and LF at rest in seven men and eight women over 70 years old after an eight-week training period. Lerma et al [36] reported higher HF values in sportswomen compared to sportsmen in the same condition. Other authors report significant differences between sedentary and athletic subjects, with higher total power and HF in athletes, but no difference in LF and ratio LF/HF [39], although in this study the sample comprised both men and women.

Therefore, to the observed data disparity in the literature, we must emphasize again that our study provides a proper number of dates matched by sex and age.

Results for the Poincaré plot pointed to significant differences for SD1 and SD2 between athletes and active subjects, both for males (Table 1) and females (Table 2), with much lower $\mathrm{p}$ values for women. There were no significant gender differences.

There are very few studies using the Poincaré plot in healthy subjects at rest but most of them report that trained people display greater parasympathetic activity than sedentary [47] or low fitness [48] subjects. Similar findings were obtained here.

Analysis of the SD2/SD1 ratio provides information on the relationship between sympathetic and parasympathetic stimuli. The present results showed a lower ratio in trained than in active subjects (male and female), although this difference was only significant for men. A lower SD2/SD1 ratio may reflect an increase in SD1, a decrease in SD2, or both. In the present sample, the diameters increased independently, but the increase in SD1 was greater than in SD2 in both men and women: SD1 increased by $35.7 \%$ in men and by $68.6 \%$ in women, while SD2 increased by $20.7 \%$ and $47.4 \%$, respectively.

An increase in SD1 means an increase in parasympathetic activity while an increase in SD2 means a decrease in sympathetic activity [27-29], so a lower ratio implies both greater parasympathetic activity and reduced sympathetic activity at rest in trained subjects.

This is not the first report of percentile data for normal subjects: Lerma et al. [36] provided gender-related data references for HRV in the time and frequency domains, using percentile 25, 50 and 75; however, their sample comprised 30 women and 20 men ranging in age from 21 to 36. Other study reporting percentiles is that of Kim and Woo [49] with korean population between 18 and 65 years old (2478 men and 735 women). They only report data for SDNN, rMSSD, LF and HF and the records are of 5 minutes. All their data are much lower than ours 
even for the same range of age (168 men and 186 women).

In conclusion, the strengths of the present study, aside from percentile distributions (Tables 3-6), are: sample size, classification according to gender and physical activity level, and values not only for the time and frequency domains but also for Poincaré plot analysis, including values for $\mathrm{pNNx}$ statistics.

\section{REFERENCES}

[1] Kaplan, D.T., Furab, M.L., Pincus, S.M., Ryan, S.M., Lipsitz, L.A. and Goldberger, A.L. (1991) Aging and the complexity of cardiovascular dynamics. Biophysical Journal, 59, 945-949. doi:10.1016/S0006-3495(91)82309-8

[2] Pikkujamsa, S.M., Makikallio, T.H., Sourander, L.B., Raiha, I.J., Puukka, P., Skytta, J., Peng, C.K., Golberger, A.L. and Huikuri, H.V. (1999) Cardiac interbeat interval dynamics from childhood to senescence: Comparison of conventional and new measures based on fractals and chaos theory. Circulation, 100, 393-399. doi:10.1161/01.CIR.100.4.393

[3] Stein, P.H.S., Kleiger, R.E. and Rottman, J.N. (1997) Differing effects of age on heart rate variability in men and women. American Journal of Cardiology, 80, 302-305. doi:10.1016/S0002-9149(97)00350-0

[4] Sinnreich, S., Kart, J.D., Friedlander, Y., Sapoznikov, D. and Luria, M.H. (1998) Five minutes recordings of heart rate variability for population studies: Repeatability and age-sex characteristics. Heart, 80, 156-162.

[5] Zhang, J. (2007) Effect of age and sex on heart rate variability in healthy subjects. Journal of Manipulative and Physiological Therapeutics, 30, 374-379.

doi:10.1016/j.jmpt.2007.04.001

[6] Carter, J.B., Banister, E.W. and Blaber, A.P. (2007) The effect of age and gender on heart rate variability after endurance training. Medicine \& Science in Sports \& Exercise, 35, 1333-1340. doi:10.1249/01.MSS.0000079046.01763.8F

[7] Huikuiri, H.V., Pikkujämsa, S.M., Airaksinen, K.E.J., Ikaheimo, M.J., Rantala, A.O., Kauma, H., Lilja, M. and Kesaniemi, Y.A. (1996) Sex-related differences in autonomic modulation of heart rate in middle-aged subjects. Circulation, 94, 122-125. doi:10.1161/01.CIR.94.2.122

[8] Ramaekers, D., Ector, H., Aubert, A.E., Rubens, A. and Werf, Van de F. (1998) Heart rate variability and heart rate in healthy volunteers. Is the female autonomic nervous system cardioprotective? European Heart Journal, 19, 1334-1341. doi:10.1053/euhj.1998.1084

[9] Cruz, De la B., López, C. and Naranjo, J. (2008) Analysis of heart rate variability at rest and during aerobic exercise. A study in healthy people and cardiac patients. British Journal of Sports Medicine, 42, 715-720.

[10] Bernardi, L., Ricordi, L., Lazzari, P., Soldá, P., Calciati, A., Ferrari, M.R., Vandea, I., Finardi, G. and Frantino, P. (1992) Impaired circadian modulation of sympathovagal activity in diabetes. Circulation, 86, 1443-1452.
doi:10.1161/01.CIR.86.5.1443

[11] Guzzetti, S., Cogliati, C., Broggi, C., Carozzi, C., Caldirolo, D., Lombardi, F. and Malliani, A. (1994) Heart period and arterial pressure variabilities in quadriplegic patients. American Journal of Physiology, 266, H1112H1120.

[12] Koh, J., Brown, T.E., Beightol, L.A., Ha, C.Y. and Eckberg, D.L. (1994) Human autonomic rhythms: Vagal cardiac mechanisms in tetraplegic patients. Journal of Physiology, 471, 483-495.

[13] Garrido, A., Cruz, de la B., Garrido, M.A., Medina, M. and Naranjo, J. (2009) Variabilidad de la frecuencia cardiaca en un deportista juvenil durante una competición de bádminton de máximo nivel. Revista Andaluza de Medicina del Deporte, 2, 70-74.

[14] Sarmiento, Y.S., Martín-González, J.M., Rodríguez-Ruiz, D., Quiroga, M.E. and García-Manso, J.M. (2009) Aplicación de la variabilidad de la frecuencia cardiaca en la caracterización de deportistas de élite de lucha canaria con diferente nivel de rendimiento. Revista Andaluza de Medicina del Deporte, 2, 120-125.

[15] Aubert, A., Seps, B. and Beckers, F. (2003) Heart rateVariability in athletes. Sports Medicine, 33, 889-919. doi:10.2165/00007256-200333120-00003

[16] Aubert, A.E., Beckers, F. and Ramaekers, D. (2001) Shortterm heart rate variability in young athletes. Journal of Cardiology, 37, 85-88.

[17] Pumprla, J., Howorka, K., Groves, D., Chester, M. and Nolan, J. (2002) Functional assessment of heart rate variability: Physiological basis and practical applications. International Journal of Cardiology, 84, 1-14.

[18] Task Force of the European Society of Cardiology and the North American Society of Pacing and Electrophysiology (1996) Heart rate variability: Standards of measurement, physiological interpretation and clinical use. Circulation, 93, 1043-1065. doi:10.1161/01.CIR.93.5.1043

[19] Woo, M.A., Stevenson, W.G., Moser, D.K., Trelense, R.B. and Harper, R.M. (1992) Patterns of beat-to-beat heart rate variability in advanced heart failure. American Heart Journal, 123, 704-710. doi:10.1016/0002-8703(92)90510-3

[20] Kleiger, R.E., Miller, J.P., Bigger, J.T. and Moss, A.J. (1987) Decreased heart rate variability and its association with increased mortality after acute myocardial infarction. The American Journal of Cardiology, 59, 256-262. doi:10.1016/0002-9149(87)90795-8

[21] Kleiger, R.E., Bosner, M.S., Rottman, J.N. and Stein, P.K. (1993) Time-domain measurements of heart rate variability. Journal of Ambulatory Monitoring, 6, 1-18.

[22] Nolan, J., Batin, P.D., Andrews, R., Lindsay, S.J., Brooksby, P., Mullen, M., Baig, W., Flapan, A.D., Cowley, A., Prescott, R.J., Neilson, J.M. and Fox, K.A. (1998) Prospective study of heart rate variability and mortality in chronic heart failure. Circulation, 98, 1510-1516. doi:10.1161/01.CIR.98.15.1510

[23] Algra, A., Tijssen, J.G.P., Poelandt, J.R.T.C., Pool, J. and Lubsen, J. (1993) Heart rate variability from 24-hour electrocardiography and the 2-year risk for sudden death. 
Circulation, 88, 180-185. doi:10.1161/01.CIR.88.1.180

[24] Gamelin, F.X., Berthoin, S. and Bosquet, L. (2006) Validity of the polar S810i Heart rate monitor to measure R-R intervals at rest. Medicine \& Science in Sports \& Exercise, 38, 887-893. doi:10.1249/01.mss.0000218135.79476.9c

[25] Mietus, J.E., Peng, C.K., Henry, I., Goldsmith, R.L. and Goldberger, A.L. (2002) The pNNx-files: Re-examining a widely-used heart rate variability measure. Heart, 88, 378-380. doi:10.1136/heart.88.4.378

[26] De la Cruz, B. and Naranjo, J. (2010) Use of pNNx statistics in the evaluation of heart rate variability at rest and during exercise. Archivos de Medicina del Deporte, 138, 181-190.

[27] Kamen, P.W., Krum, H. and Tonkin, A.M. (1996) Poincaré plots of heart rate variability allows quantitative display of parasympathetic nervous activity in humans. Clinical Science, 91, 201-208.

[28] Tulppo, M.P., Mäkikallio, T.H., Takala, T.E.S., Seppänen, T. and Huikuri, H.V. (1996) Quantitative beat-to-beat analysis of heart rate dynamics during exercise. American Journal of Physiology, 271, H244-H252.

[29] Toichi, M., Sugiera, T., Murai, T. and Sengoku, A. (1997) A new method of assessing cardiac autonomic function and its comparison with spectral analysis and coefficient of variation of R-R interval. Journal of the Autonomic Nervous System, 62, 79-84. doi:10.1016/S0165-1838(96)00112-9

[30] Nunan, D., Sandercock, G.R.H. and Brodie, D.A. (2010) A quantitave systematic review of normal values for short-term heart rate variability in healthy adults. Pacing and Clinical Electrophysiology, 33, 1407-1417. doi:10.1111/j.1540-8159.2010.02841.x

[31] Zulfiqar, U., Jurivich, D.A., Gao, W. and Singer, D.H. (2010) Relation of high heart rate variability to healthy longevity. American Journal of Cardiology, 105, 11811185. doi:10.1016/j.amjcard.2009.12.022

[32] Kuo, T.B., Lin, T., Yang, C.C., Li, C.L., Chen, C.F. and Chou, P. (1999) Effect of aging on gender differences in neural control of heart rate. American Journal of Physiology: Heart and Circulatory Physiology, 277, H2233H2239.

[33] Migliaro, E.R., Contreras, P., Bech, S., Etxagibel, A., Castro, M., Ricca, R. and Vicente, K. (2001) Relative influence of age, resting heart rate and sedentary life style in short-term analysis of heart rate variability. Brazilian Journal of Medical and Biological Research, 34, 493-500. doi:10.1590/S0100-879X2001000400009

[34] Ribeiro, T.F., Azevedo, G.D., Crescêncio, J.C., Marães, V.R.F.S., Papa, V., Catai, A.M., Verzola, R.M.M., Oliveira, L., Silva, de Sá M.F., Gallo, L. and Silva, E. (2001) Heart rate variability under resting conditions in postmenopausal and young women. Brazilian Journal of Medical and Biological Research, 34, 871-877. doi:10.1590/S0100-879X2001000700006

[35] Soejima, K., Akaishi, M., Oyamada, K., Meguro, T., Mitamura, H. and Ogawa, S. (1999) Influence of age on ambulatory electrocardiogram-derived heart rate variability. Canadian Journal of Cardiology, 15, 181-184.
[36] Lerma, C., Vallejo, M., Urias, K., Hermosillo, A. and Cárdenas, M. (2006) Diferencias en la modulación autónoma del corazón entre mujeres y hombres. Archivos de cardiología de México, 76, 277-282.

[37] Berkoff, D.J., Cairns, C.B., Sanchez, L.D. and Moorman, C.T. (2007) Heart rate variability in elite American trackand-field athletes. Journal of Strength \& Conditioning Research, 21, 227-231. doi:10.1519/00124278-200702000-00041

[38] Sandercock, G.R.H., Bromley, P.D. and Brodie, D.A. (2005) Effects of exercise on heart rate variability: Inferences from meta-analysis. Medicine \& Science in Sports \& Exercise, 37, 433-439. doi:10.1249/01.MSS.0000155388.39002.9D

[39] Gregoire, J., Tuck, S., Yamamoto, Y. and Hughson, R.L. (1996) Heart rate variability at rest and exercise: Influence of age, gender, and physical training. Canadian Journal of Applied Physiology, 21, 455-470. doi:10.1139/h96-040

[40] Maciel, B.C., Gallo, L., Marin, N.J., Lima, E.C. and Martins, L.E.B. (2003) Effects of aerobic training on heart rate. Revista Brasileira de Medicina do Esporte, 9, 104-112.

[41] Goldsmith, R.L., Bloomfield, D.M. and Rosenwinkel, E.T. (2000) Exercise and autonomic function. Coronary Artery Disease, 11,129-135. doi:10.1097/00019501-200003000-00007

[42] Bigger, J.T., Fleiss, J.L., Steinman, R.C., Rolnitzky, L.M., Kleiger, R.E. and Rottman, J.N. (1992) Frequency domain measures of heart period variability and mortality after myocardial infarction. Circulation, 85,164-171. doi:10.1161/01.CIR.85.1.164

[43] Hadasa, M., Azume, A., Zen, K., Asada, S., Kawasaki, T., Kamitavi, T., Kawasaki, S., Sugihara, H. and Matsubara, H. (2004) Very low frequency power of heart rate variability is a powerful predictor of clinical prognosis in patients with chronic heart failure. Circulation Journal, 68, 343-347. doi:10.1253/circj.68.343

[44] Guzzetti, S., Mezzetti, S., Magatelli, R., Porta, A., De Angelis, G., Rovelli, G. and Malliani, A. (2000) Linear and non-linear 24 h heart rate variability in chronic heart failure. Autonomic Neuroscience, 86, 114-119. doi:10.1016/S1566-0702(00)00239-3

[45] La Rovere, M.T., Pinna, G.D., Maestri, R., Mortara, A., Capomolla, J., Febo, O., Ferrari, R., Franchini, M., Gnemmi, M., Opasich, C., Riccardi, P.G., Traversi, E. and Cobelli, F. (2003) Short-term heart rate variability strongly predicts sudden cardiac death in chronic heart failure patients. Circulation, 107, 565-570. doi:10.1161/01.CIR.0000047275.25795.17

[46] Perini, R., Fisher, N., Veicsteinas, A. and Pendergast, D.R. (2002) Aerobic training and cardiovascular responses at rest and during exercise in older men and women. Medicine \& Science in Sports \& Exercise, 34, 700-708. doi:10.1097/00005768-200204000-00022

[47] Mourot, L., Bouhaddi, M., Perrey, S., Cappelle, S., Henriet, M.T., Wolf, J.P., Rouillon, J.D. and Regnard. J. (2004) Decrease in heart rate variability with overtraining: Assessment by the Poincaré plot analysis. Clinical Physiology and Functional Imaging, 24, 10-18. 
doi:10.1046/j.1475-0961.2003.00523.x

[48] Capdevila, L., Rodas, G., Ocaña, M., Parrado, E., Pintanel, M. and Valero, M. (2008) Variabilidad de la frecuencia cardiaca como indicador de salud en el deporte: Validación con un cuestionario de calidad de vida (SF-12).
Apunts Medicine, 158, 62-69.

[49] Kim, G.M. and Woo, J.M. (2011) Determinants for heart rate variability in a normal Korean population. Journal of Korean Medicine Science, 26, 1293-1298.

doi:10.3346/jkms.2011.26.10.1293 